\title{
Standard Measurement Procedure for Soil Radon Exhalation Rate and Its Uncertainty
}

\author{
Jihye Seo ${ }^{1,2}$, Muttaqin Margo Nirwono ${ }^{1,3, *}$, Seong Jin Park ${ }^{1,2}$, Sang Hoon Lee ${ }^{1,2}$ \\ ${ }^{1}$ School of Achitectural, Civil, Environmental and Energy Engineering, Kyungpook National University, Daegu, Korea; ${ }^{2}$ Radiation Science Research Institute, \\ Kyungpook National Univesity, Daegu, Korea; ${ }^{3}$ Badan Pengawas Tenaga Nuklir, Jakarta, Indonesia
}

\section{Technical Paper}

Received February 17, 2018

Revision March 20, 2018

Accepted March 22, 2018

\section{Corresponding author:}

Muttaqin Margo Nirwono

School of Achitectural, Civil, Environmental and Energy Engineering, Kyungpook National University, 80 Daehak-ro, Buk-gu, Daegu 41566, Korea

Tel: $+82-10-5948-5071$

Fax: +82-53-950-8979

E-mail:m.margo@bapeten.go.id
Background: Radon contributing about $42 \%$ of annual average dose, mainly comes from soil. In this paper, standard measurement procedures for soil radon exhalation rate are suggested and their measurement uncertainties are analyzed.

Materials and Methods: We used accumulation method for estimating surface exhalation rate. The closed-loop measurement system was made up with a RAD7 detector and a surface chamber. Radon activity concentrations in the system were observed as a function of time, with data collection of 5 and 15-minute and the measurement time of 4 hours. Linear and exponential fittings were used to obtain radon exhalation rates from observed data. Standard deviations of measurement uncertainties for two approaches were estimated using usual propagation rules.

Results and Discussion: The exhalation rates (E) from linear approach, with 30 minutes measurement time were $44.8-48.6 \mathrm{mBq} \cdot \mathrm{m}^{-2} \cdot \mathrm{s}^{-1}$ or $2.14-2.32$ atom $\cdot \mathrm{cm}^{-2} \cdot \mathrm{s}^{-1}$ with relative measurement uncertainty of about $10 \%$. The contributions of fitting parameter A, volume (V) and surface (S) to the estimated measurement uncertainty of $E$ were $59.8 \%, 30.1 \%$ and $10.1 \%$, in average respectively. In exponential fitting, at 3-hour measurement we had E ranged of 51.6-69.2 $\mathrm{mBq} \cdot \mathrm{m}^{-2} \cdot \mathrm{s}^{-1}$ or $2.46-3.30$ atom $\cdot \mathrm{cm}^{-2} \cdot \mathrm{s}^{-1}$ with about $15 \%$ relative uncertainty. Fitting with 4 -hour measurement resulted $\mathrm{E}$ about $51.3-68.2 \mathrm{mBq} \cdot \mathrm{m}^{-2} \cdot \mathrm{s}^{-1}$ or $2.45-3.25$ atom $\cdot \mathrm{cm}^{-2} \cdot \mathrm{s}^{-1}$ with $10 \%$ relative uncertainty. The uncertainty contributions in exponential approach were $75.1 \%, 13.4 \%$, $8.7 \%$, and $2.9 \%$ for total decay constant $\mathrm{k}$, fitting parameter $\mathrm{B}, \mathrm{V}$, and $\mathrm{S}$, respectively.

Conclusion: In obtaining exhalation rates, the linear approach is easy to apply, but by saturation feature of radon concentrations, the slope tends to decrease away from the expected slope for extended measurement time. For linear approach, measurement time of 1-hour or less was suggested. For exponential approach, the obtained exhalation rates showed similar values for any measurement time, but measurement time of 3-hour or more was suggested for about $10 \%$ relative uncertainty.

Keywords: Soil radon, Exhalation rate, Uncertainty, RAD7

\section{Introduction}

Radon, ${ }^{222} \mathrm{Rn}$, is an alpha-emitting radioactive substance which belongs to the decay chain starting from ${ }^{238} \mathrm{U}$ and has a half-life of 3.8 days. Since radon is a noble gas in nature and the half-life of radon is longer than that of isotopes ${ }^{220} \mathrm{Rn}$ (55 seconds) and ${ }^{223} \mathrm{Rn}$ (3.96 seconds), it can escape and diffuse from the earthly rock and soil to the air by diffusion and pressure difference. It is considered to be the second reason of death 
caused by lung cancer [1] because inhaled radon and its daughter product can irradiate the lung [2]. Radiations are carcinogenic. For human being, naturally-occurring ${ }^{222} \mathrm{Rn}$ is a common source of radiation exposure from inhaled and tissue-deposited radionuclides, and the ${ }^{232} \mathrm{Th}$ exposure which occurs in soil, is less common. Cancers associated with exposure to particular nuclides, usually in an occupational context, include lung cancer, bone sarcomas, liver cancer, leukemia and thyroid cancer [3].

In UNSCEAR 2008 report it is summarized that annual average doses from radiation exposure are $2.4 \mathrm{mSv}$ by natural sources and $0.6 \mathrm{mSv}$ by artificial sources. Among all the natural/artificial sources the inhalation of radon gases contributes the most, $1.26 \mathrm{mSv}$ which is about $42 \%$ of the total annual dose $3.0 \mathrm{mSv}$ as shown in Figure 1. The main source of radon is mostly the soil and underlying geology [4]. Soil radon contributes about $69 \%$ of all radon sources [1]. From the soil, radon is mainly transported by air pressure differences to the indoor occupied space [4]. For outdoor, radon levels are mainly determined by the soil characteristics, such as the content of uranium and radium, porosity, and the consequent radon exhalation rate; local topology; and the conditions of meteorology [5]. In the estimation of level of radon in the environment, survey of soil exhalation rate measurement is important [6].

Radon exhalation from the ground surface affects both in- door and outdoor radon activity concentrations. For this reason, radon exhalation process from soil to atmosphere is needed further clarification [5]. The exhalation rate of radon can be measured by active and passive methods [5]. Active method uses continuous radon monitors such RAD7, AlphaGUARD, and examples of passive method involve charcoal or solid-state alpha track detectors which are passive in detection principle and take long exposure time. In short term period, Reimer suggested to conduct the active measurement for making risk determination and mitigation of radon concentration [7]. In developed studies, the measurement method of soil radon exhalation rate was commonly based on the closed loop systems to accumulate radon using a surface chamber that mounted on the soil surface [8].

In this study, the authors used RAD7 and a surface chamber to form an active closed loop system and took radon exhalation measurements from Daegu soil with different time intervals ( 5 minutes and 15 minutes). Using the measured data the exhalation rates were obtained from two different fittings, linear and exponential. Finally, the authors made suggestions on the detailed standard measurement procedures, based on the associated uncertainties of the exhalation rates. These suggestions will be useful in large area mapping of radon exhalation rate, which is essential in radon risk studies and potential mitigation actions.

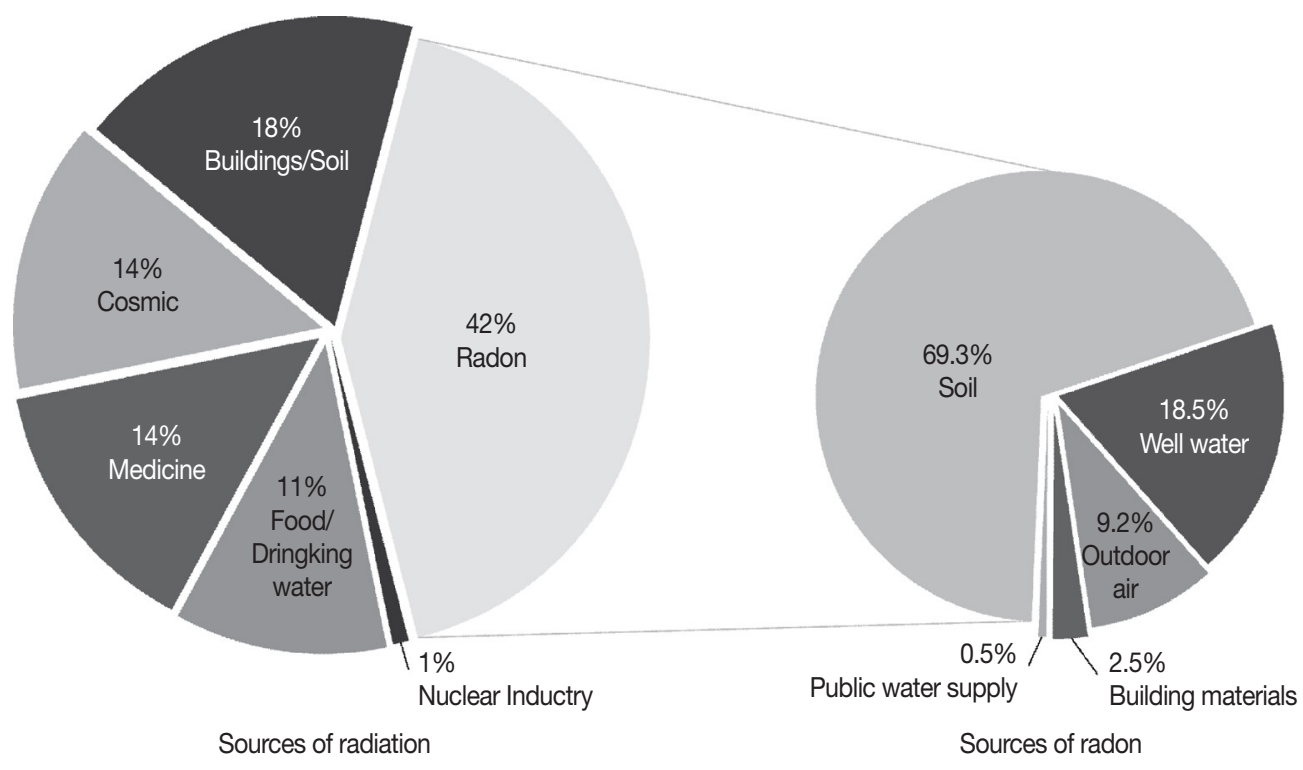

Fig. 1. Sources of radiation exposure [1] and radon. ${ }^{1)}$

1) Marble Institute of America. The Truth About Granite \& Radon/Radiation. IV(1). 2007;1-4. 


\section{Materials and Methods}

\section{Soil Exhalation Rate Measurement}

An active closed-loop system consisting of a RAD7 radon detector, a surface chamber placed on top of surface soil, a drying unit and connecting tubes, as shown in Figure 2, based on ISO standard [9], was used for radon exhalation rate measurement. The procedure that based on the ISO as follow:

1) Choosing and locating the measuring point.

2) Recording the location of the measuring point.

3) Preparing the surface to be investigated if necessary by removing for example, rock, roots, and grass.

4) Installing the soil surface emission chamber on the surface of the soil under investigation.

5) Setting the RAD7 in place.

6) Purging the accumulation container with radon-free air.

7) Making air tightness between the container and the surface under investigation.

8) Performing the accumulation of radon in the container.
9) Monitoring the variations of the radon activity concentration measured by the RAD7 for a period of measuring time.

10) Recording the date and time of the accumulation process.

11) Reading the data (radon activity concentration) recorded during the accumulation process.

12) Calculating the surface exhalation rate.

Air and radon from the soil is sucked into the RAD7 and the exhaust gas from RAD7 is returned to the surface chamber by the RAD7 pump and the reported flow rate is about $0.7161 \cdot \mathrm{min}^{-1}$. Inside the RAD7 the key alpha spectrometer is a passive implanted planner silicon (PIPS) detector and in normal mode the RAD7 achieves better precision by counting ${ }^{218} \mathrm{Po}$ and ${ }^{214} \mathrm{Po}$ alpha peaks. In sniff mode only, the peaks from ${ }^{218} \mathrm{Po}$ are counted. As shown in Table 1 the total volume of the closed system was about $1.93 \mathrm{~L}$ and the area of surface chamber was about $366 \mathrm{~cm}^{2}$.

The actual measurements were conducted in Daegu, Korea during 2017 autumn months. A sampling spot was con-

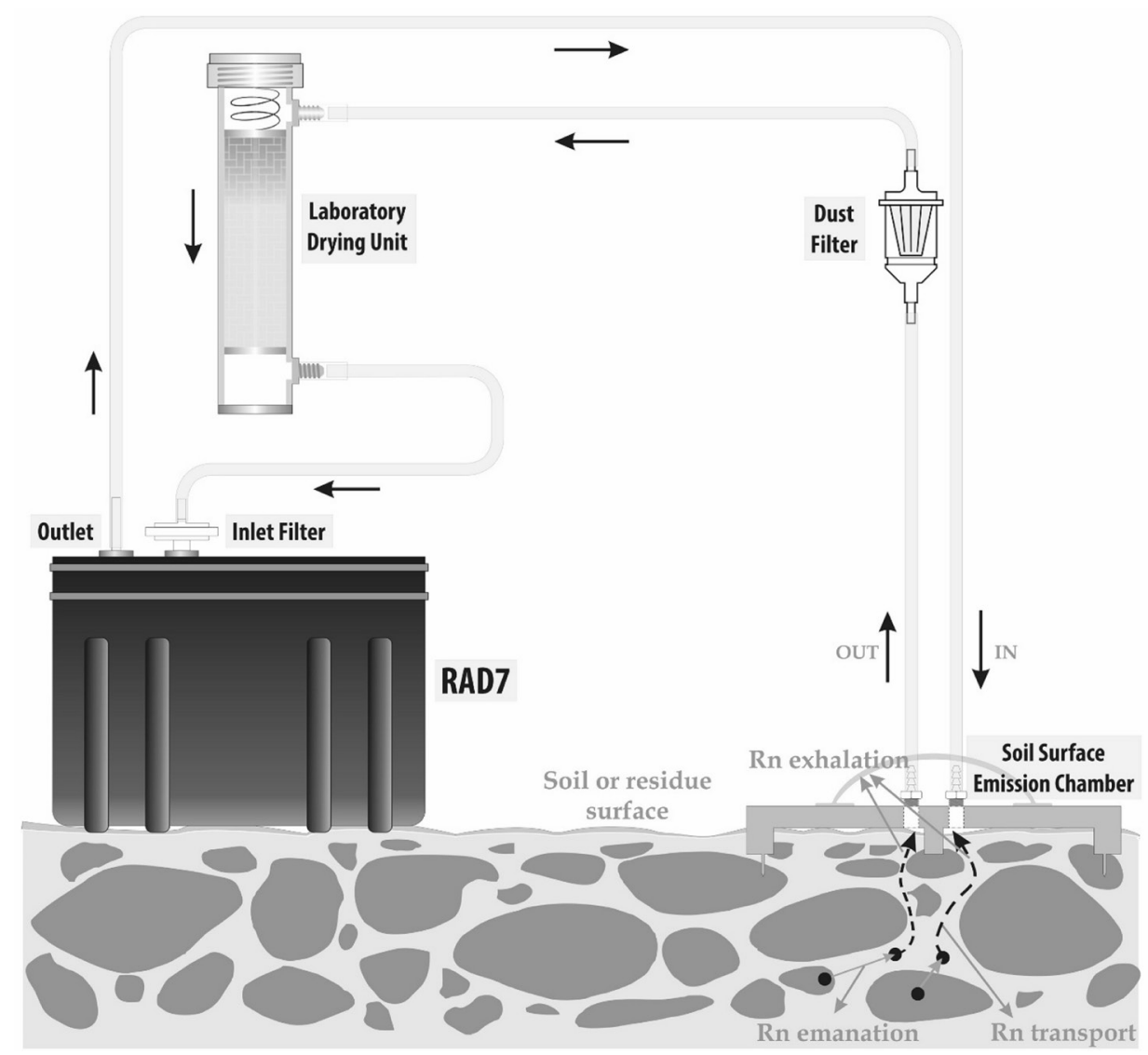

Fig. 2. A closed-loop radon exhalation rate measurement scheme using RAD7. 
Table 1. RAD7 Detecting System Technical Parameters

\begin{tabular}{lcc}
\hline Parameter & Value & Unit \\
\hline Area of the surface chamber, $S$ & $(3,664 \pm 68) \times 10^{-5}$ & $\mathrm{~m}^{2}$ \\
Volume of the whole system, $V$ & $(1,931 \pm 62) \times 10^{-6}$ & $\mathrm{~m}^{3}$ \\
Decay constant of ${ }^{222} \mathrm{Rn}, \lambda$ & $2.0979 \times 10^{-6}$ & $\mathrm{~s}^{-1}$
\end{tabular}

ducted about $0.5 \mathrm{~km}$ from the previous study [10] was selected and rainy days were avoided. According to time interval of 5 and 15-minute, data 1 and data 2 were divided, respectively. Then, this measurement was conducted on 3 different days that the letter is intended to after number. In conducting short-term continuous sampling, time intervals that have been used by other researchers were 10, 12, 15, 20, 40, 60-minute or 2 hours $[4,5,7,11-14] .^{2)}$ In this study, radon data were collected with 5 and 15-minute periods during total measurement time of 4 hours. For each measurement before placing the surface chamber on top of the soil, the RAD7 detector was purged with fresh outdoor air for 1 hour by the pump air circulation to remove pre-existing radon gas in the chamber.

\section{Balance Equation}

When the radon exhalation rate, $\mathrm{E}\left(\mathrm{Bq} \cdot \mathrm{m}^{-2} \cdot \mathrm{s}^{-1}\right)$, from the soil surface is assumed constant, the changes in $\mathrm{C}(\mathrm{t})$, the radon concentration of the system in $\mathrm{Bq} \cdot \mathrm{m}^{-3}$, can be expressed with the radon influx term and the decay term as given in Equation 1. The radon exhalation rate is also expressed as $E_{A}$ (atom $\cdot \mathrm{m}^{-2} \cdot \mathrm{s}^{-1}$ ) in terms of the atom. In real cases, one should consider two more terms which account for leakage effect and back-diffusion in Equation 2. Two constants of leakage effect and back diffusion, $\lambda_{1}$ and $\lambda_{b}$, have the same dimension $\left(\mathrm{s}^{-1}\right)$ as physical decay constant $\lambda$. For leakage effect, we may assume that the outside radon concentration $\mathrm{C}_{\text {out }}$ is zero because it will remain very small (near to zero) when compared with detecting system radon or soil radon concentrations. With this assumption $\left(\mathrm{C}_{\mathrm{out}}=0\right)$ and an initial zero condition, Equation 3 is the solution to the differential equation and well describes the radon concentration of detecting system as a function of time during measurement. And $\mathrm{V}\left(\mathrm{m}^{3}\right)$ is certain volume of detector chamber and soil surface area of chamber is used as $\mathrm{S}\left(\mathrm{m}^{2}\right)$.

$$
\frac{d C}{d t}=\frac{\lambda \cdot E_{A} \cdot S}{V}-\lambda \cdot C=\frac{E \cdot S}{V}-\lambda \cdot C
$$

$$
\begin{aligned}
& \frac{d C}{d t}=\frac{E \cdot S}{V}-\lambda \cdot C-\lambda_{1} \cdot\left(C-C_{\text {out }}\right)-\lambda_{b} \cdot C \\
& C(t)=\frac{E \cdot S}{V \cdot\left(\lambda+\lambda_{1}+\lambda_{b}\right)}\left(1-e^{-\left(\lambda+\lambda_{1}+\lambda_{b}\right) \cdot t}\right)
\end{aligned}
$$

The radon concentration given in Equation 3 will increase linearly in the beginning of measurement and the approximated trend is given in Equation 4. At the end $\mathrm{C}(\mathrm{t})$ will be saturated at the limiting value given in Equation 5.

$$
\begin{gathered}
C(t)=\frac{E \cdot S}{V} t \\
C(t=\infty)=\frac{E \cdot S}{V \cdot\left(\lambda+\lambda_{1}+\lambda_{b}\right)}
\end{gathered}
$$

\section{Exhalation Rate Acquisition from Fitting}

By comparing measured radon concentrations with the model function in Equation 3 one can get the radon exhalation rate from the soil. In detailed analysis we tried two methods, linear and exponential. Linear fitting focused on the initial increase phase given in Equation 4 and a limited portion of measurement data were used. In exponential fitting, whole measurement data were used along with Equation 3. Microsoft Excel and Origin Pro were used for data fitting. In statistical analysis, the estimated variation of measurement uncertainty of system parameters and fitting parameters were used to get final the estimated variation of measurement uncertainty of exhalation rates.

\section{1) Linear Fitting}

Linear fitting is suitable for initial or beginning part of radon concentration change, see Figure 3, legend 1. The fitting parameters might follow below equation.

$$
\mathrm{y}=\mathrm{At}
$$

where

$$
A=\frac{S \cdot E}{V}
$$

It consists of parameters that can be measured like S, V, A, and a parameter, $\mathrm{E}$ that we need for this study.

The value of the radon exhalation rate, E can be expressed as

$$
\mathrm{E}=\frac{\mathrm{A} \cdot \mathrm{V}}{\mathrm{S}}
$$

2) DURRIDGE. Emission Chambers: Bulk and Surface Emission Detection for the RAD7, User Manual, no. 978. 2016;4-9. 
And the propagation of uncertainty of $\mathrm{E}$ is determined from the uncertainties of $\mathrm{A}, \mathrm{V}$, and $\mathrm{S}$ :

$$
\frac{\sigma_{\mathrm{E}}}{\mathrm{E}}=\sqrt{\left(\frac{\sigma_{\mathrm{A}}}{\mathrm{A}}\right)^{2}+\left(\frac{\sigma_{\mathrm{V}}}{\mathrm{V}}\right)^{2}+\left(\frac{\sigma_{\mathrm{S}}}{\mathrm{S}}\right)}
$$

Thus, the contribution to uncertainty of $\mathrm{E}$ is

$$
\left(\frac{\sigma_{A}}{\mathrm{~A}} / \frac{\sigma_{\mathrm{E}}}{\mathrm{E}}\right)^{2}+\left(\frac{\sigma_{\mathrm{V}}}{\mathrm{V}} \frac{\sigma_{\mathrm{E}}}{\mathrm{E}}\right)^{2}+\left(\frac{\sigma_{\mathrm{S}}}{\mathrm{S}} \frac{\sigma_{\mathrm{E}}}{\mathrm{E}}\right)^{2}=1
$$

Where the contribution of each parameter to uncertainty

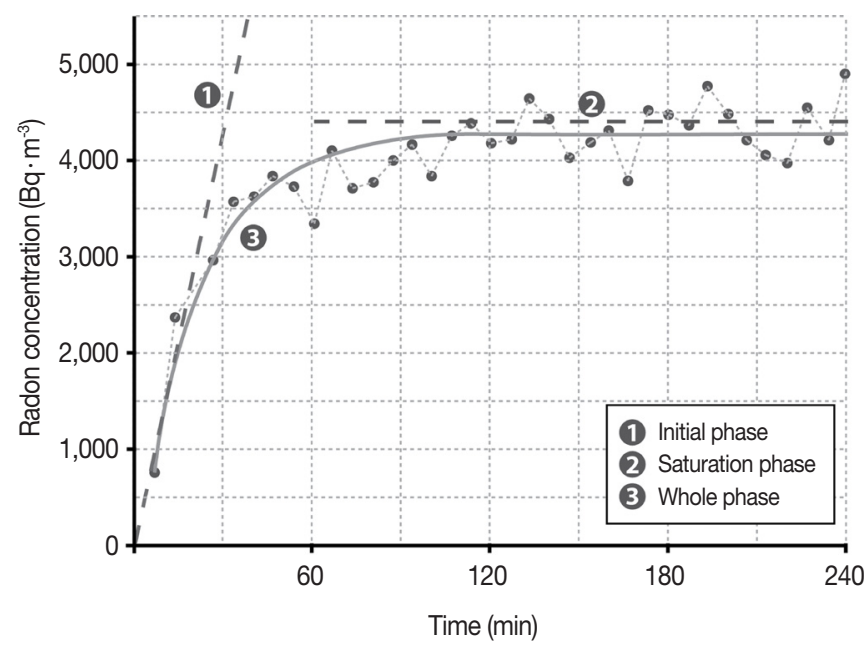

Fig. 3. Radon concentration change and fitting graph by interval according to measuring time.
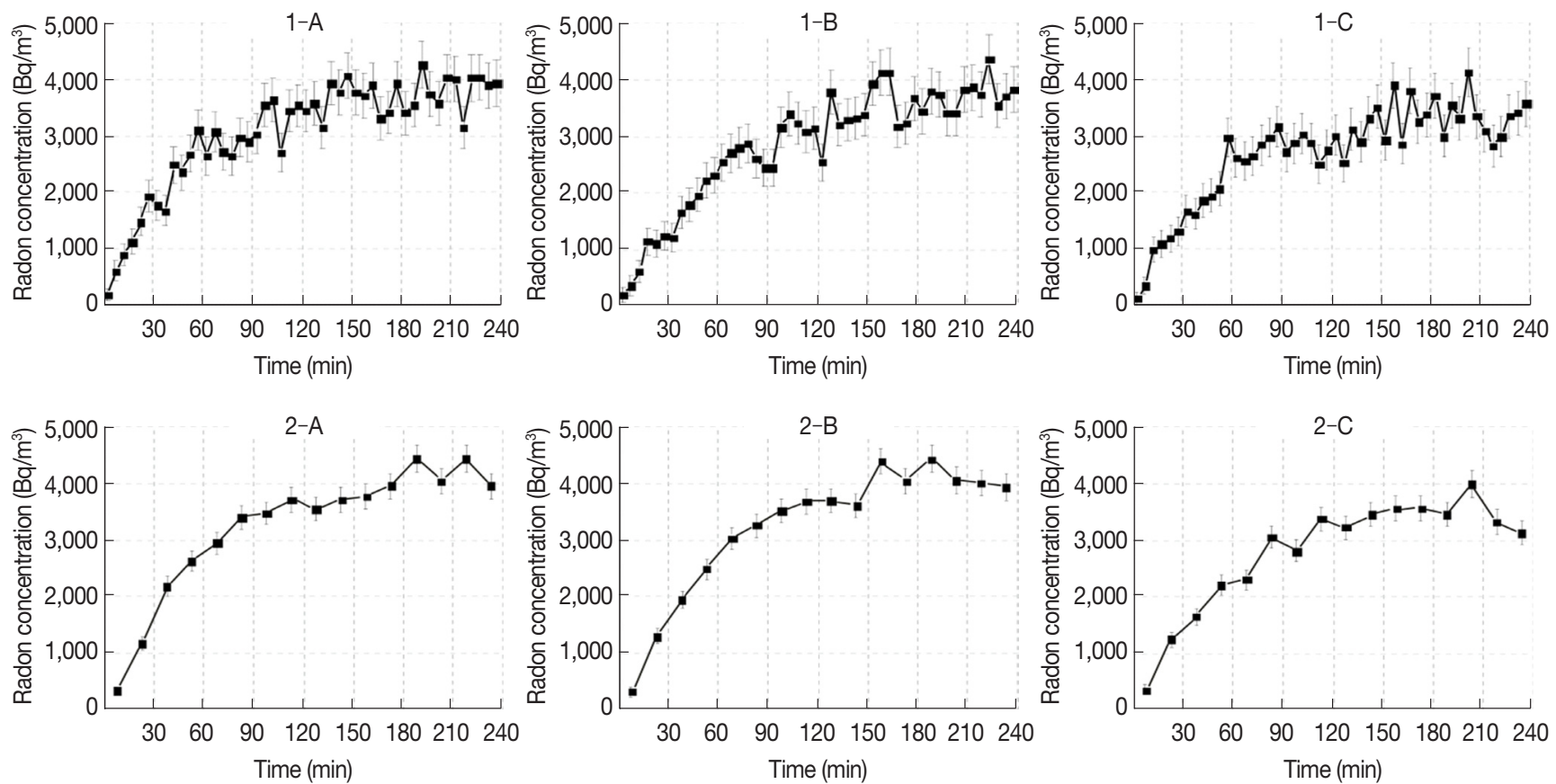

Fig. 4. Measurement data of radon concentration of 5 and 15-minute interval time. 
$\left(\frac{\sigma_{\mathrm{B}}}{\mathrm{B}} / \frac{\sigma_{\mathrm{E}}}{\mathrm{E}}\right)^{2}+\left(\frac{\sigma_{\mathrm{V}}}{\mathrm{V}} / \frac{\sigma_{\mathrm{E}}}{\mathrm{E}}\right)^{2}+\left(\frac{\sigma_{\mathrm{k}}}{\mathrm{k}} / \frac{\sigma_{\mathrm{E}}}{\mathrm{E}}\right)^{2}+\left(\frac{\sigma_{\mathrm{S}}}{\mathrm{S}} / \frac{\sigma_{\mathrm{E}}}{\mathrm{E}}\right)^{2}=1$

\section{Results and Discussion}

Radon concentration increased linearly in initial part of measurement and, after a certain period of time, tended to be maintained at similar value as Figure 3. Since measurement started at radon-free, exhalation of radon gas from soil caused concentration increment. But, with the leakage and back diffusion effect, radon concentration reached saturation feature for extended measurement time. In this study, the detail of radon data were shown in Figure 4 and radon average concentration is $2,986 \pm 20 \mathrm{~Bq} \cdot \mathrm{m}^{-3}$.

Radon exhalation rate from soil surface was calculated by Equation 7 in case of linear fitting and Equation 10 in event of exponential fitting.

\section{Linear Fitting}

Figure 5 shows the linear fitting of data 1-A that had 5 minutes time interval. It was based on Equation 7. It could be seen that after 1 hour measurement, the slope is bending down. Furthermore, the remaining data are worthless. Tables 2 and 3 show the linear fitting of data of 5 and 15-minute time interval, respectively.

It can be seen from the Tables 2 and 3 that the increment of $t$ will be followed by declining the value of $A$ and $E$, furthermore the slope will be bending down as shown in Figure 5. So, in measurement time of more than 1-hour, the value of E may tended to be underestimated.
Authors preferred that 1-hour or less measurement is considerate as the appropriate time. Then, 30 minutes measurement had about $10 \%$ relative measurement uncertainty and the slopes were not really bending down. In this measurement, the study concluded that $\mathrm{E}$ was ranged of $44.8-48.6 \mathrm{mBq} \cdot \mathrm{m}^{-2} \cdot \mathrm{s}^{-1}$ and the range of $\mathrm{E}_{\mathrm{A}}$ was 2.139-2.316 atom $\cdot \mathrm{cm}^{-2} \cdot \mathrm{s}^{-1}$.

In linear fitting analysis of soil radon exhalation rate, three parameters that were $\mathrm{A}, \mathrm{V}$ and $\mathrm{S}$ affected to the propagation of uncertainty, of which the influence is the order of $\mathrm{E}, \mathrm{V}$, and $\mathrm{S}$. The most contributor to uncertainty of radon exhalation rate is the parameter of $A$ that ranged between $60.8-87.9 \%$ in 30 minutes measurement. And the average of A contribution is $59.75 \%$, $\mathrm{V}$ is $30.13 \%$, and $\mathrm{S}$ is $10.13 \%$.

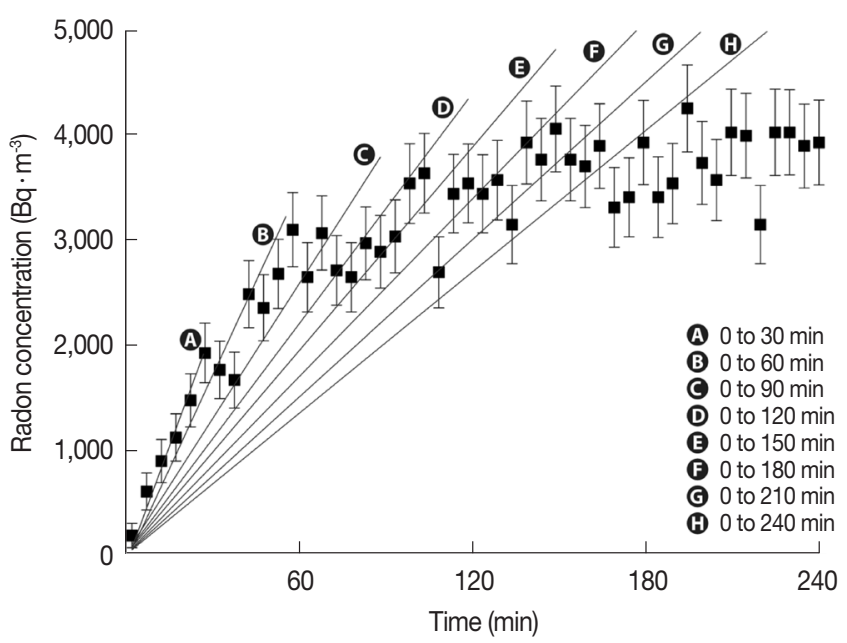

Fig. 5. Linear fitting of data 1-A.

Table 2. Linear Fitting of 5-minute Time Interval Data

\begin{tabular}{|c|c|c|c|c|c|c|c|c|}
\hline \multirow[b]{2}{*}{ Data } & \multirow[b]{2}{*}{$\underset{(\min )}{\mathrm{t}}$} & \multirow{2}{*}{$\begin{array}{c}\text { Fitting parameter } \\
\begin{array}{c}\mathrm{A} \\
\left(\mathrm{Bq} \cdot \mathrm{m}^{-3} \cdot \mathrm{s}^{-1}\right)\end{array}\end{array}$} & \multirow[b]{2}{*}{$\begin{array}{c}\mathrm{E} \\
\left(\mathrm{mBq} \cdot \mathrm{m}^{-2} \cdot \mathrm{s}^{-1}\right)\end{array}$} & \multirow[b]{2}{*}{$\begin{array}{c}E_{A} \\
\text { (atoms } \cdot \mathrm{cm}^{-2} \cdot \mathrm{s}^{-1} \text { ) }\end{array}$} & \multirow[b]{2}{*}{$\begin{array}{c}\sigma_{E} / E \\
(\%)\end{array}$} & \multicolumn{3}{|c|}{ Relative contributions to uncertainty } \\
\hline & & & & & & $\begin{array}{c}\left(\frac{\sigma_{A}}{A} / \frac{\sigma_{E}}{E}\right)^{2} \\
(\%)\end{array}$ & $\underset{(\%)}{\left(\frac{\sigma_{V}}{V} / \frac{\sigma_{E}}{E}\right)^{2}}$ & $\begin{array}{c}\left(\frac{\sigma_{S}}{S} / \frac{\sigma_{E}}{E}\right)^{2} \\
(\%)\end{array}$ \\
\hline \multirow[t]{4}{*}{$1-\mathrm{A}$} & 0 to 120 & $0.380 \pm 0.007$ & $20.1 \pm 0.8$ & $0.96 \pm 0.04$ & 4.1 & 18.8 & 60.8 & 20.4 \\
\hline & 0 to 90 & $0.478 \pm 0.010$ & $25.2 \pm 1.1$ & $1.20 \pm 0.05$ & 4.2 & 24.5 & 56.5 & 19.0 \\
\hline & 0 to 60 & $0.621 \pm 0.017$ & $32.7 \pm 1.5$ & $1.56 \pm 0.07$ & 4.6 & 35.9 & 48.0 & 16.1 \\
\hline & 0 to 30 & $0.923 \pm 0.042$ & $48.6 \pm 2.9$ & $2.32 \pm 0.14$ & 5.9 & 60.8 & 29.4 & 9.9 \\
\hline \multirow[t]{4}{*}{$1-B$} & 0 to 120 & $0.559 \pm 0.017$ & $29.5 \pm 1.4$ & $1.40 \pm 0.07$ & 4.7 & 39.6 & 45.2 & 15.2 \\
\hline & 0 to 90 & $0.636 \pm 0.024$ & $33.5 \pm 1.8$ & $1.60 \pm 0.08$ & 5.3 & 51.0 & 36.6 & 12.3 \\
\hline & 0 to 60 & $0.726 \pm 0.039$ & $38.2 \pm 2.5$ & $1.82 \pm 0.12$ & 6.6 & 68.4 & 23.6 & 8.0 \\
\hline & 0 to 30 & $0.862 \pm 0.091$ & $45.5 \pm 5.1$ & $2.17 \pm 0.24$ & 11.1 & 89.0 & 8.2 & 2.8 \\
\hline \multirow[t]{4}{*}{$1-C$} & 0 to 120 & $0.549 \pm 0.017$ & $28.9 \pm 1.4$ & $1.38 \pm 0.07$ & 4.8 & 40.4 & 44.6 & 15.0 \\
\hline & 0 to 90 & $0.680 \pm 0.025$ & $35.8 \pm 1.9$ & $1.71 \pm 0.09$ & 5.2 & 49.2 & 38.0 & 12.8 \\
\hline & 0 to 60 & $0.779 \pm 0.041$ & $41.1 \pm 2.6$ & $1.96 \pm 0.13$ & 6.4 & 66.6 & 25.0 & 8.4 \\
\hline & 0 to 30 & $0.922 \pm 0.092$ & $48.6 \pm 5.1$ & $2.32 \pm 0.25$ & 10.6 & 87.9 & 9.1 & 3.1 \\
\hline
\end{tabular}


Table 3. Linear Fitting of 15-minute Time Interval Data

\begin{tabular}{|c|c|c|c|c|c|c|c|c|}
\hline \multirow[b]{2}{*}{ Data } & \multirow[b]{2}{*}{$\underset{(\min )}{\mathrm{t}}$} & \multirow{2}{*}{$\begin{array}{c}\text { Fitting parameter } \\
\qquad \begin{array}{c}\mathrm{A} \\
\left(\mathrm{Bq} \cdot \mathrm{m}^{-3} \cdot \mathrm{s}^{-1}\right)\end{array}\end{array}$} & \multirow[b]{2}{*}{$\begin{array}{c}E \\
\left(\mathrm{mBq} \cdot \mathrm{m}^{-2} \cdot \mathrm{s}^{-1}\right)\end{array}$} & \multirow[b]{2}{*}{$\begin{array}{c}E_{A} \\
\left.\text { (atoms } \cdot \mathrm{cm}^{-2} \cdot \mathrm{s}^{-1}\right)\end{array}$} & \multirow[b]{2}{*}{$\begin{array}{c}\sigma_{E} / E \\
(\%)\end{array}$} & \multicolumn{3}{|c|}{ Relative contributions to uncertainty } \\
\hline & & & & & & $\begin{array}{c}\left(\frac{\sigma_{A}}{A} / \frac{\sigma_{E}}{E}\right)^{2} \\
(\%)\end{array}$ & $\left(\frac{\sigma_{V}}{V} / \frac{\sigma_{E}}{E}\right)^{2}$ & $\begin{array}{c}\left(\frac{\sigma_{S}}{S} / \frac{\sigma_{E}}{E}\right)^{2} \\
(\%)\end{array}$ \\
\hline \multirow[t]{4}{*}{$2-A$} & 0 to 120 & $0.668 \pm 0.017$ & $35.2 \pm 1.5$ & $1.68 \pm 0.08$ & 4.5 & 32.2 & 50.7 & 17.1 \\
\hline & 0 to 90 & $0.772 \pm 0.024$ & $40.7 \pm 1.9$ & $1.94 \pm 0.09$ & 4.9 & 42.4 & 43.1 & 14.5 \\
\hline & 0 to 60 & $0.879 \pm 0.039$ & $46.3 \pm 2.6$ & $2.21 \pm 0.13$ & 5.8 & 59.7 & 30.2 & 10.1 \\
\hline & 0 to 30 & $0.851 \pm 0.080$ & $44.8 \pm 4.5$ & $2.14 \pm 0.22$ & 10.2 & 86.8 & 9.9 & 3.3 \\
\hline \multirow[t]{4}{*}{$2-B$} & 0 to 120 & $0.660 \pm 0.017$ & $34.8 \pm 1.5$ & $1.66 \pm 0.08$ & 4.5 & 33.5 & 49.8 & 16.8 \\
\hline & 0 to 90 & $0.752 \pm 0.024$ & $39.6 \pm 1.9$ & $1.89 \pm 0.09$ & 4.9 & 44.1 & 41.8 & 14.1 \\
\hline & 0 to 60 & $0.841 \pm 0.039$ & $44.3 \pm 2.6$ & $2.11 \pm 0.13$ & 6.0 & 62.4 & 28.2 & 9.5 \\
\hline & 0 to 30 & $0.916 \pm 0.088$ & $48.2 \pm 4.9$ & $2.30 \pm 0.24$ & 10.3 & 87.2 & 9.6 & 3.2 \\
\hline \multirow[t]{4}{*}{$2-\mathrm{C}$} & 0 to 120 & $0.571 \pm 0.016$ & $30.1 \pm 1.4$ & $1.44 \pm 0.07$ & 4.7 & 37.3 & 46.9 & 15.8 \\
\hline & 0 to 90 & $0.656 \pm 0.023$ & $34.5 \pm 1.7$ & $1.65 \pm 0.08$ & 5.1 & 48.3 & 38.7 & 13.0 \\
\hline & 0 to 60 & $0.756 \pm 0.038$ & $39.8 \pm 2.5$ & $1.90 \pm 0.12$ & 6.3 & 65.5 & 25.8 & 8.7 \\
\hline & 0 to 30 & $0.916 \pm 0.088$ & $48.3 \pm 4.9$ & $2.30 \pm 0.24$ & 10.3 & 87.2 & 9.6 & 3.2 \\
\hline
\end{tabular}

\section{Exponential Fitting}

Figure 6 shows plotting of exponential fitting of data 1-A that had trend align since 2.5 hours measurement. The first 30-minute measurement was inappropriate data to do exponential fitting, since the curve shown opposite direction to other time ranges. Furthermore, it was excluded from analyzing using this method. As a result of exponential fitting that can be seen on Tables 4 and 5, the range of $\mathrm{E}$ was 47.6$73.1 \mathrm{mBq} \cdot \mathrm{m}^{-2} \cdot \mathrm{s}^{-1}$ and $\mathrm{E}_{\mathrm{A}}$ was ranged of 2.27-3.48 atom $\cdot \mathrm{cm}^{-2}$. $\mathrm{s}^{-1}$, unlike that of linear fitting, it does not change greatly depending on the measurement interval or time. However, the relative measurement uncertainty decreases with the measurement time increase, $17.65 \%$ for 2 hours, $11.00 \%$ for 3 hours, and $9.05 \%$ for 4 hours. For relative uncertainty level below 15\%, 3 hour measurement was chosen that had $\mathrm{E}$ range of 51.6-69.2 $\mathrm{mBq} \cdot \mathrm{m}^{-2} \cdot \mathrm{s}^{-1}$ and $\mathrm{E}_{\mathrm{A}} 2.46-3.30$ atom $\cdot \mathrm{cm}^{-2} \cdot \mathrm{s}^{-1}$. For better result of measurement, below $10 \%$ relative uncertainty, 4 hours and more measurement time is needed or about $51.3-68.2 \mathrm{mBq} \cdot \mathrm{m}^{-2} \cdot \mathrm{s}^{-1}$ and $\mathrm{E}_{\mathrm{A}} 2.45-3.25$ atom $\cdot \mathrm{cm}^{-2} \cdot \mathrm{s}^{-1}$. Exponential fitting had four parameters which were $\mathrm{B}, \mathrm{V}, \mathrm{k}$ and $\mathrm{S}$. The most contributor to uncertainty of $\mathrm{E}$ is $\mathrm{k}$ that charged the average of $75.1 \%$ and the uncertainty contributions were $13.4 \%, 8.7 \%$, and $2.9 \%$ for $\mathrm{B}, \mathrm{V}$, and S, respectively.

In Table 3, the relative measurement uncertainty of E decreases by time and when measurement time is 30 minutes, it ranges from 0.97-1.45, at 2 hours, it shown 0.13-0.16 and at 4 hours, 0.08-0.09. On the other hand, in Table 4, at 1 hour measurement, it ranges from 0.60-7.87, it shown unstable. Starting from 2 hours, it is shown that the relative uncertainty is stable from $0.09-0.23$. It can be concluded that for stable

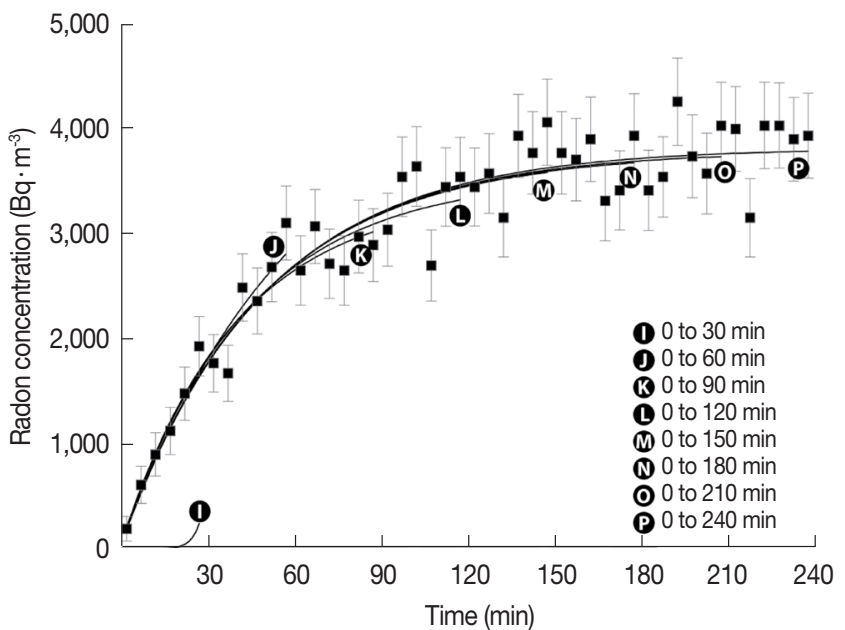

Fig. 6. Exponential fitting of data 1-A.

data, the measurement time is suggested more than 2 hours.

In Figure 7, at 5 minutes interval time, the relative measurement uncertainty of E ranges from 0.13-0.16; at 10-minute, 0.14-0.17 and for interval time of 15, 20 and 30-minute, it shown that more unstable relative uncertainties. Interval time is suggested whether 5 or 10 -minute.

\section{Continuously Soil Radon Exhalation Rate Measurement procedure}

After investigation using linear and exponential fitting of exhalation rate, we proposed the procedure of continuously measurement of the soil radon exhalation rate as flowchart of Figure 8. The procedure measurement follows the ISO until step 7, then before performing the accumulation of radon, it should be decided the time measurement. Based on the 
Table 4. Exponential Fitting of 5-minute Time Interval Data

\begin{tabular}{|c|c|c|c|c|c|c|c|c|c|c|}
\hline \multirow[b]{2}{*}{ Data } & \multirow[b]{2}{*}{$\stackrel{t}{t}$} & \multicolumn{2}{|c|}{ Fitting parameter } & \multirow[b]{2}{*}{$\begin{array}{c}E \\
\left(\mathrm{mBq} \cdot \mathrm{m}^{-2} \cdot \mathrm{s}^{-1}\right)\end{array}$} & \multirow[b]{2}{*}{$\begin{array}{c}E_{A} \\
\left(\text { atoms } \cdot \mathrm{cm}^{-2} \cdot \mathrm{s}^{-1}\right)\end{array}$} & \multirow[b]{2}{*}{$\begin{array}{c}\sigma_{E} / E \\
(\%)\end{array}$} & \multicolumn{4}{|c|}{ Relative contributions to uncertainty } \\
\hline & & $\begin{array}{c}\mathrm{B} \\
\left(\mathrm{Bq} \cdot \mathrm{m}^{-3} \cdot \mathrm{s}^{-1}\right)\end{array}$ & $\begin{array}{c}k \\
\left(10^{-5} \cdot \mathrm{s}^{-1}\right)\end{array}$ & & & & $\begin{array}{c}\left(\frac{\sigma_{B}}{B} / \frac{\sigma_{E}}{E}\right)^{2} \\
(\%)\end{array}$ & $\begin{array}{c}\left(\frac{\sigma_{K}}{K} / \frac{\sigma_{E}}{E}\right)^{2} \\
(\%)\end{array}$ & $\begin{array}{c}\left(\frac{\sigma_{V}}{V} / \frac{\sigma_{E}}{E}\right)^{2} \\
(\%)\end{array}$ & $\begin{array}{c}\left(\frac{\sigma_{S}}{S} / \frac{\sigma_{E}}{E}\right)^{2} \\
(\%)\end{array}$ \\
\hline \multirow[t]{4}{*}{$1-A$} & 0 to 240 & $3,819 \pm 78$ & $33.9 \pm 2.2$ & $68.2 \pm 5.2$ & $3.25 \pm 0.16$ & 7.7 & 7.1 & 70.0 & 17.3 & 5.8 \\
\hline & 0 to 180 & $3,776 \pm 112$ & $34.8 \pm 2.8$ & $69.2 \pm 6.4$ & $3.30 \pm 0.16$ & 9.2 & 10.3 & 74.0 & 12.0 & 4.0 \\
\hline & 0 to 120 & $3,556 \pm 185$ & $39.0 \pm 4.5$ & $73.1 \pm 9.7$ & $3.48 \pm 0.17$ & 13.3 & 15.3 & 77.0 & 5.8 & 1.9 \\
\hline & 0 to 60 & $4,608 \pm 1,217$ & $27.4 \pm 10.0$ & $66.4 \pm 30.1$ & $3.17 \pm 0.15$ & 45.2 & 34.1 & 65.0 & 0.5 & 0.2 \\
\hline \multirow[t]{4}{*}{$1-B$} & 0 to 240 & $3,888 \pm 104$ & $25.0 \pm 1.8$ & $51.3 \pm 4.3$ & $2.45 \pm 0.12$ & 8.4 & 10.2 & 70.0 & 14.5 & 4.9 \\
\hline & 0 to 180 & $3,869 \pm 176$ & $25.3 \pm 2.6$ & $51.6 \pm 6.0$ & $2.46 \pm 0.12$ & 11.7 & 15.2 & 75.0 & 7.5 & 2.5 \\
\hline & 0 to 120 & $3,828 \pm 281$ & $25.9 \pm 3.4$ & $52.3 \pm 8.1$ & $2.49 \pm 0.12$ & 15.6 & 22.3 & 72.0 & 4.2 & 1.4 \\
\hline & 0 to 60 & $4,049 \pm 1,150$ & $23.7 \pm 9.0$ & $50.5 \pm 24.0$ & $2.41 \pm 0.11$ & 47.5 & 35.8 & 64.0 & 0.5 & 0.2 \\
\hline \multirow[t]{4}{*}{$1-C$} & 0 to 240 & $3,359 \pm 82$ & $34.1 \pm 2.6$ & $60.4 \pm 5.4$ & $2.88 \pm 0.14$ & 8.9 & 7.5 & 75.0 & 12.9 & 4.4 \\
\hline & 0 to 180 & $3,332 \pm 116$ & $34.7 \pm 3.2$ & $60.9 \pm 6.5$ & $2.90 \pm 0.14$ & 10.6 & 10.7 & 77.0 & 9.0 & 3.0 \\
\hline & 0 to 120 & $3,259 \pm 186$ & $36.4 \pm 4.5$ & $62.6 \pm 8.8$ & $2.98 \pm 0.14$ & 14.0 & 16.5 & 77.0 & 5.2 & 1.7 \\
\hline & 0 to 60 & $4,093 \pm 1,479$ & $25.6 \pm 1.3$ & $55.3 \pm 33.8$ & $2.64 \pm 0.13$ & 61.0 & 35.0 & 65.0 & 0.3 & 0.1 \\
\hline
\end{tabular}

Table 5. Exponential Fitting of 15-minute Time Interval Data

\begin{tabular}{|c|c|c|c|c|c|c|c|c|c|c|}
\hline \multirow[b]{2}{*}{ Data } & \multirow[b]{2}{*}{$\stackrel{\mathrm{t}}{(\mathrm{min})}$} & \multicolumn{2}{|c|}{ Fitting parameter } & \multirow[b]{2}{*}{$\begin{array}{c}E \\
\left(\mathrm{mBq} \cdot \mathrm{m}^{-2} \cdot \mathrm{s}^{-1}\right)\end{array}$} & \multirow[b]{2}{*}{$\begin{array}{c}\mathrm{E}_{\mathrm{A}} \\
\left(\text { atoms } \cdot \mathrm{cm}^{-2} \cdot \mathrm{s}^{-1}\right)\end{array}$} & \multirow[b]{2}{*}{$\begin{array}{c}\sigma_{E} / E \\
(\%)\end{array}$} & \multicolumn{4}{|c|}{ Relative contributions to uncertainty } \\
\hline & & $\begin{array}{c}\mathrm{B} \\
\left(\mathrm{Bq} \cdot \mathrm{m}^{-3} \cdot \mathrm{s}^{-1}\right)\end{array}$ & $\begin{array}{c}\mathrm{k} \\
\left(10^{-5} \cdot \mathrm{s}^{-1}\right)\end{array}$ & & & & $\begin{array}{c}\left(\frac{\sigma_{\mathrm{B}}}{\mathrm{B}} / \frac{\sigma_{\mathrm{E}}}{\mathrm{E}}\right)^{2} \\
(\%)\end{array}$ & $\begin{array}{c}\left(\frac{\sigma_{K}}{K} / \frac{\sigma_{E}}{E}\right)^{2} \\
(\%)\end{array}$ & $\begin{array}{c}\left(\frac{\sigma_{V}}{V} / \frac{\sigma_{E}}{E}\right)^{2} \\
(\%)\end{array}$ & $\left(\frac{\sigma_{S}}{S} / \frac{\sigma_{E}}{E}\right)^{2}$ \\
\hline \multirow[t]{4}{*}{$2-\mathrm{A}$} & 0 to 240 & $4,289 \pm 129$ & $27.5 \pm 2.3$ & $62.2 \pm 5.9$ & $2.97 \pm 0.28$ & 9.5 & 10.1 & 74.8 & 11.3 & 3.8 \\
\hline & 0 to 180 & $4,200 \pm 186$ & $34.8 \pm 3.0$ & $63.2 \pm 7.5$ & $3.01 \pm 0.36$ & 11.9 & 14.0 & 76.3 & 7.3 & 2.4 \\
\hline & 0 to 120 & $4,903 \pm 565$ & $39.0 \pm 4.3$ & $58.3 \pm 13.2$ & $2.78 \pm 0.63$ & 22.6 & 26.0 & 71.4 & 2.0 & 0.7 \\
\hline & 0 to 60 & $42,084 \pm 231,189$ & $2.1 \pm 12.0$ & $47.6 \pm 374.3$ & $2.27 \pm 17.84$ & 787.1 & 48.7 & 51.3 & 0.0 & 0.0 \\
\hline \multirow[t]{4}{*}{ 2-B } & 0 to 240 & $4,307 \pm 123$ & $14.5 \pm 2.1$ & $61.9 \pm 5.6$ & $2.95 \pm 0.27$ & 9.1 & 9.8 & 73.6 & 12.4 & 4.2 \\
\hline & 0 to 180 & $4,457 \pm 205$ & $25.0 \pm 2.6$ & $59.9 \pm 7.0$ & $2.85 \pm 0.34$ & 11.8 & 15.4 & 74.8 & 7.4 & 2.5 \\
\hline & 0 to 120 & $4,886 \pm 427$ & $25.3 \pm 3.2$ & $57.2 \pm 9.9$ & $2.73 \pm 0.47$ & 17.3 & 25.5 & 69.9 & 3.4 & 1.1 \\
\hline & 0 to 60 & $8,650 \pm 8,351$ & $11.1 \pm 12.0$ & $50.6 \pm 74.2$ & $2.41 \pm 3.54$ & 146.7 & 43.3 & 56.6 & 0.0 & 0.0 \\
\hline \multirow[t]{4}{*}{$2-C$} & 0 to 240 & $3,653 \pm 122$ & $29.1 \pm 2.8$ & $56.1 \pm 6.0$ & $2.67 \pm 0.29$ & 10.7 & 9.7 & 78.5 & 8.9 & 3.0 \\
\hline & 0 to 180 & $3,856 \pm 159$ & $26.2 \pm 2.4$ & $53.1 \pm 5.7$ & $2.53 \pm 0.27$ & 10.8 & 14.6 & 73.7 & 8.8 & 3.0 \\
\hline & 0 to 120 & $3,959 \pm 447$ & $25.1 \pm 5.0$ & $52.4 \pm 12.1$ & $2.5 \pm 0.58$ & 23.1 & 23.8 & 73.7 & 1.9 & 0.6 \\
\hline & 0 to 60 & $4,067 \pm 1,445$ & $24.8 \pm 12.0$ & $53.1 \pm 31.6$ & $2.53 \pm 1.51$ & 59.5 & 35.6 & 64.0 & 0.3 & 0.1 \\
\hline
\end{tabular}

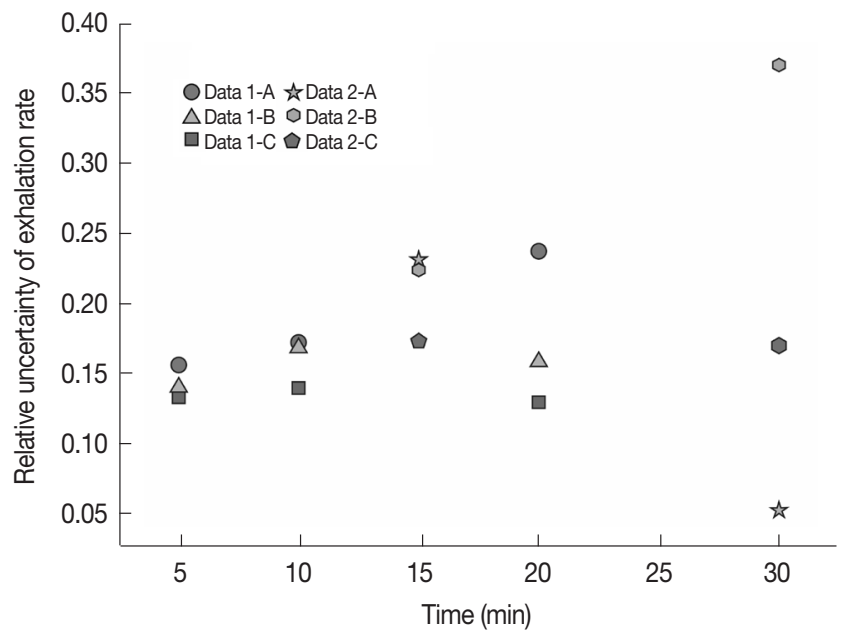

Fig. 7. Relative uncertainties compare with time interval at 2 hours measurement. investigation, it categorized as below and above one hour measurement. When an hour measurement is chosen, the linear fitting approach will be used for calculation of exhalation rate. On the other hand, exponential fitting method is preferred for above an hour measurement.

\section{Conclusion}

An active closed-loop system consisting of a RAD7 radon detector, a surface chamber mounted on the soil surface, a drying unit and connecting tubes was used to measure soil radon exhalation rates. The measured radon concentrations showed initial linear increase in the beginning and reached a certain saturation level due to leakage and back diffusion. The linear and exponential fitting methods were applied to 


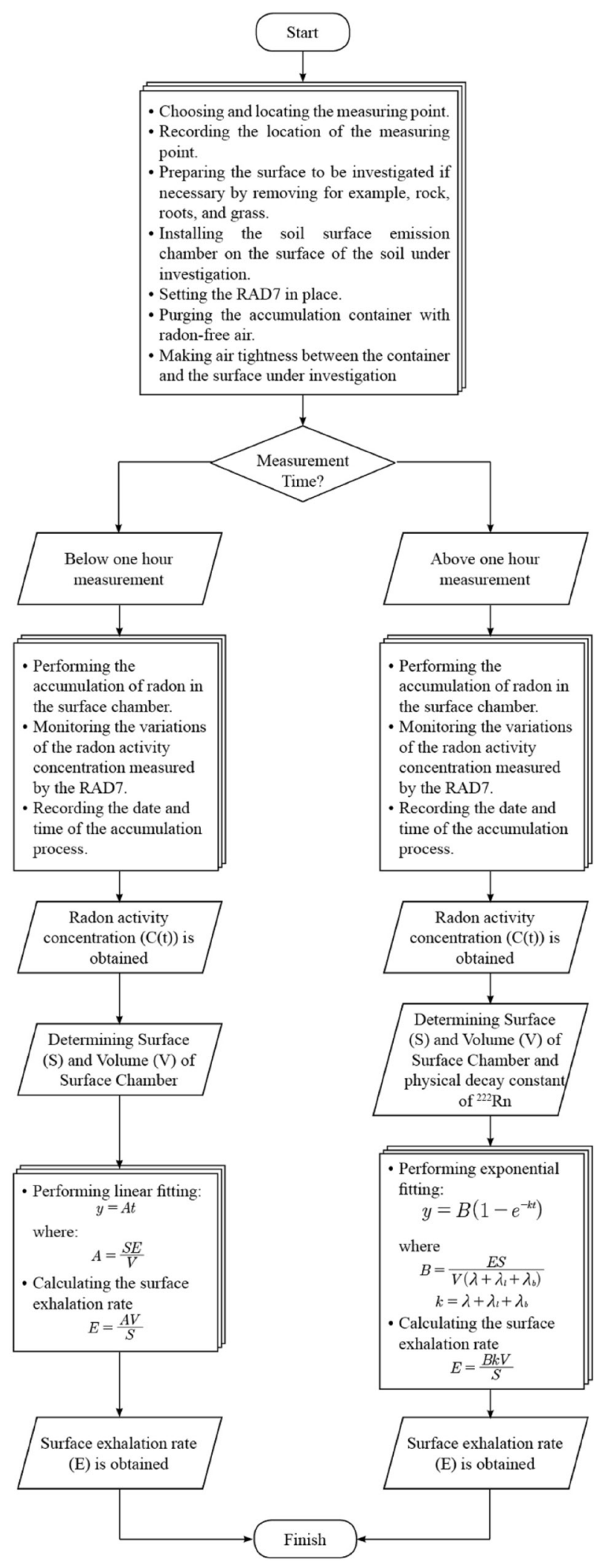

Fig. 8. Flowchart of continuously soil radon exhalation rate measurement procedure. get radon exhalation rates from measured radon concentration data. Detailed uncertainty analysis was performed to get suggestions on standard procedures.

Radon concentration from soil increases at the beginning part of measurement and tends to saturate due to leakage and back diffusion effects. So, linear fitting is good and simple, nevertheless it has the problem when adding some data, the slope will be bending down. Therefore, the longer the measurement time, the smaller the relative measurement uncertainty but the lower the radon exhalation rate from soil that obtained by increasing slope of radon concentration. Radon exhalation rate (E) of soil surface that gave about $10 \%$ of relative uncertainty level was about $44.8-48.6 \mathrm{mBq} \cdot \mathrm{m}^{-2} \cdot \mathrm{s}^{-1}$ and $E_{A}$ was ranged of 2.139-2.316 atom $\cdot \mathrm{cm}^{-2} \cdot \mathrm{s}^{-1}$ for 30 minutes measurement in linear fitting method. One hour measurement may result in a lower uncertainty, but bending down may already occur and the $\mathrm{E}$ value may be underestimated. It is suggested 1 hour measurement that had relative uncertainty below $10 \%$ for measurement time. In this method, three parameters which are fitting parameter (A), volume of the system (V) and area of surface chamber (S) were involved in calculating the exhalation rate and uncertainty. On average contribution, A contributes $59.75 \%$, $\mathrm{V}$ is $30.13 \%$, and $\mathrm{S}$ is $10.13 \%$.

Exponential fitting had similar values of $\mathrm{E}$ regardless of the measurement time. And the relative measurement uncertainty decreased as the measurement time became longer. The uncertainty was reduced rapidly in 2 hours measurement, however it is suggested that measurement time is more than 3 hours for a relative uncertainty level below $12.5 \%$. And its interval time is recommended of 5 and 10 minutes. Radon exhalation rate for exponential fitting was 51.6-69.2 $\mathrm{mBq} \cdot \mathrm{m}^{-2} \cdot \mathrm{s}^{-1}$ and $\mathrm{E}_{\mathrm{A}}$ was 2.46-3.30 atom $\cdot \mathrm{cm}^{-2}$ using 3 hours measurement. Exponential fitting with 4 hours measurement time case resulted in reduced $10 \%$ relative uncertainty. In this fitting, two fitting parameters (fitting parameter [B] and total decay constant [k]) were parted of four exhalation rate parameters that two others are V and S. Among them, $\mathrm{k}$ which is the major uncertainty contributor was charged the average of $75.1 \%$, B had $13.4 \%$, $\mathrm{V}$ had $8.7 \%$, and $S$ had $2.9 \%$ in average relative uncertainty.

The result of radon exhalation from soil surface of Daegu was $44.8-48.6 \mathrm{mBq} \cdot \mathrm{m}^{-2} \cdot \mathrm{s}^{-1}$ or $2.139-2.316$ atom $\cdot \mathrm{cm}^{-2} \cdot \mathrm{s}^{-1}$ for 30 minutes measurement in linear fitting method and 51.6$69.2 \mathrm{mBq} \cdot \mathrm{m}^{-2} \cdot \mathrm{s}^{-1}$ or $2.46-3.30$ atom $\cdot \mathrm{cm}^{-2}$ for exponential fitting using 3 hours measurement. 
This study can contribute to radon measurement standard procedures. And, radon study from soil and rocks, which are sources of indoor radon gas, can be used as base data for radon mapping and selecting radon hazard areas.

\section{References}

1. Baskaran M. Radon: a tracer for geological, geophysical and geochemical studies. 19th Ed. Newyork NY. Springer Publishing. 2016;229.

2. Haque AK, Al-Affan IA. Main factors affecting the calculation of radiation dose to the lung from inhalation of radon daughters. Sci. Total Environ. 1988;74:279-289.

3. Boyle P, Levin B. World Cancer report 2008. 1st Ed. Lyon, France. International Agency for Research on Cancer. 2008;512.

4. Tan Y, Xiao D. Measurement of the radon exhalation rate from the medium surface by tracing the radon concentration. J. Radioanal. Nucl. Chem. 2013;295(3):2295-2299.

5. International Commission on Radiation Units and Measurements. Measurement and Reporting of Radon Exposures. ICRU Report 88. J. ICRU. 2012;12(2):1-24.

6. Sun K, Guo Q, Zhuo W. Feasibility for Mapping Radon Exhalation Rate from Soil in China. J. Nucl. Sci. Technol. 2004;41(1):8690.

7. Shahrokhi A, Burghele BD, Fábián F, Kovács T. New study on the correlation between carbon dioxide concentration in the environment and radon monitor devices. J. Environ. Radioact. 2015; 150:57-61.

8. Nasab MM, Negarestani A. Processing the spike- like radon anomaly exhalation from the soil surface by electrical model. Appl. Radiat. Isot. 2017;125:4-8.

9. International Organization of Standardization. Measurement of radioactivity in the environment- Air: Radon-222 Part 7: Accumulation method for estimating surface exhalation rate. ISO 11665-7. 2012;1-22.

10. Seo J. Measurement of radon exhalation rate and study on correlation between radon exhalation rate and other environmental radiation parameters of soil in Youngnam area. Kyungpook National University. Master's Thesis. 2017;17-23.

11. Vanchhawng SL. Measurement of radon, thoron and their progeny concentrations in Mizoram with special reference to Aizawl, Champhai and Kolasib districts. Mizoram University. Doctoral Thesis. 2012;68.

12. Tan Y, Xiao D. Measuring radon exhalation rate through three cycles. J. Instrum. 2012;7(8):T08004.

13. Reimer GM. Radon measurement uncertainty: comparison between passive short-term and active measurement. J. Radioanal. Nucl. Chem. 2008;277(1):249-251.

14. Freiler Á, Horváth Á, Török K, Földes T. Origin of radon concentration of Csalóka Spring in the Sopron Mountains (West Hungary). J. Environ. Radioact. 2016;151:174-184. 